\title{
MIGRAÇÃO E IMAGEM: PERSPECTIVAS TEÓRICAS DA RETÓRICA VISUAL
}

\author{
Suzana Ramos Coutinho \\ PUC / São Paulo \\ sucoutinho@gmail.com
}

\begin{abstract}
Resumo: O tema da mobilidade humana tem sido uma discussão central nas Ciências Humanas. Ainda que a proliferação e aceleração de migrantes transnacionais e a questão do que eles representam para diferentes pessoas e sociedades tenha se tornado uma questão central nos últimos anos, o advento da "era das migrações" ainda se constitui um desafio para o campo das Ciências Humanas, uma vez que suscita novos problemas epistemológicos e a demanda por novas metodologias e formas de representação. A proposta aqui é discutir, a partir de elementos teóricos, como se dá a construção das retóricas visuais em torno da experiência migrante. A imagem aqui se apresenta como objeto de reflexão sobre a responsabilidade de desconstruir estereótipos, buscando novas e transformadoras formas de visibilidade que não reproduzam meramente o discurso visual do governo ou dos meios de comunicação de massa, mas "desafiar a ordem política estabelecida revelando o que propositadamente e deliberadamente escondido, articulando o que ainda não foi dito e sugerindo alternativas viáveis ao status quo" (KÖHN 2016, p. 4).
\end{abstract}

Palavras-chave: Migração. Mídia. Fotografia. Política.

\begin{abstract}
The human mobility has been a central discussion in the Human Sciences. Even though the proliferation and acceleration of transnational migrants and the question of what they represent to different people and societies has become a central issue in recent years, the advent of the "migration era" still constitutes a challenge for the field of humanities, as it raises new epistemological problems and the demand for new methodologies and forms of representation. The proposal here is to discuss, from a theoretical perspective, how the construction of visual rhetoric around the migrant experience takes place. The image here presents itself as an object of reflection on the responsibility to deconstruct stereotypes, seeking new and transforming forms of visibility that do not merely reproduce the visual discourse of the government or the mass media, but "challenge the established political order by revealing what is purposefully and deliberately hidden, articulating what has not yet been said and suggesting viable alternatives to the status quo" (KÖHN 2016, p. 4).
\end{abstract}

Keywords: Migration. Media. Photography. Politics. 


\section{Introdução}

O tema da mobilidade humana tem sido uma discussão central nas ciências humanas. Ainda que a proliferação e aceleração de migrantes transnacionais e a questão do que eles representam para diferentes pessoas e sociedades tenha se tornado uma questão relevante nos últimos anos, o advento da "era das migrações" (CASTLES, DE HAAS, MILLER, 2014) ainda se constitui um desafio para o campo das ciências humanas, uma vez que suscita novos problemas epistemológicos e a demanda por novas metodologias e formas de representação. As migrações atuais têm ganhado alcances globais devido a globalização dos mercados financeiros, das inovações tecnológicas, comunicações e meios de transportes. Os movimentos de pessoas deram forma a Estados e Sociedades desde tempos imemoráveis. O que é distinto nos anos recentes é seu alcance global, suas características para a política nacional e internacional e as consequências econômicas e sociais. Os movimentos de pessoas em grande número surgem do acelerado processo de integração global. Movimentos de mercadorias e de capital quase sempre fazem surgir movimentos de pessoas. A era das migrações deverá se prolongar e se intensificar devido a alguns motivos: crescente desigualdade; pressões políticas; ecológicas, religiosas, demográficas; conflitos étnicos / políticos; áreas de livre comércio. Diversos autores têm indicado algumas tendências nos estudos migratórios como a globalização da migração, (onde cada vez mais países serão lugares de partida, destino ou trânsito), diversidade das motivações para migrar (trabalho, refúgio, clima etc.), feminização da migração e, por fim, a politização da migração (CASTLES, DE HAAS, MILLER, 2014).

Este artigo traz discussões parciais referente ao projeto de pesquisa em andamento chamado "Religião e Migração: investigação de uma retórica visual", financiado pelo Pipeq /PUC-São Paulo. Minha proposta aqui é pensar criticamente algumas possibilidades teóricas em torno da construção das retóricas visuais da experiência migrante presentes na mídia convencional. No contexto deste artigo me proponho a discutir não somente categorias migratórias genéricas, mas a pensar sobre pessoas, movimentos e a demanda por novas categorias e reflexões visuais que ultrapassem as perspectivas já estabelecidas, de modo a auxiliar a reflexão sobre os múltiplos aspectos políticos e transformadores da imagem.

Como categoria de análise, me uno a outros pesquisadores (NETO, FERREIRA, 2005) com o entendimento que os estudos migratórios são um campo de investigação científica que indaga 
sobre os "movimentos espaciais de população (...) qualificando e quantificando as regularidades encontradas, relacionando tais processos à formação de identidades (...) e procurando extrair consequências em termos de formas de intervenção, estatal ou não, com vistas ao contexto social mais amplo" (NETO, FERREIRA, 2005, p. 10). Do mesmo modo, o significado tradicional da palavra migração (tanto do ponto de vista acadêmico quanto do senso comum) remete ao estabelecimento de indivíduos ou grupos num país do qual não são nacionais e que os acolhe nessa situação liminar.

Baeninger (2012) aponta para o fato de que as novas modalidades da imigração internacional representam, no cenário da globalização, a definição e redefinição de espaços transacionais (conforme GLICK et al., 1997). A autora afirma que a importância do fenômeno migratório internacional reside hoje muito mais em suas especificidades, "em suas diferentes intensidades e espacialidades e em seus impactos diferenciados (particularmente ao nível local) do que no volume de imigrantes envolvidos nos deslocamentos populacionais" (BAENINGER, 2012, p. 9).

O deslocamento enquanto fenômeno coletivo e individual é um movimento com diferentes etapas e perspectivas que, dependendo dos interesses temáticos das várias disciplinas que o elegem como objeto de estudo inclui, conforme Santos, Petros e Loureiro (2014) três possíveis abordagens: a) a emigração (ou as múltiplas condições sociais, políticas, econômicas, etc. e que motivam o deslocamento), b) as questões sociais decorrentes do estabelecimento temporário ou definitivo em outro país e c) os desdobramentos através da obtenção de novos espaços (inclusive na arena política) objetivando a "integração numa outra sociedade e/ou construindo a diferença cultural (etnicidade) e formas de pertencimento coletivo que podem produzir debates, antagonismos e desigualdades sociais" (p. 11).

É necessário ter em mente que, dentro deste contexto, há diferentes tipologias que acabam por compor um quadro heterogêneo dos processos migratórios, com reflexos inclusive nas suas construções teóricas. Categorias como migrantes, deslocados, refugiados, exilados, itinerantes, ilegais acabam por se tornar "rótulos" que "priorizam o sistema mundial e a demanda de mão de obra” (SANTOS, PETRUS, LOUREIRO, 2014, p. 11) em uma abordagem que enfatiza sobretudo os aspectos econômicos e políticos do processo migratório. E se há uma multiplicidade de categorias e construções teóricas em torno dos processos migratórios (para mais, ver DURAND, LUSSI, 2015), a mesma multiplicidade é vista na construção da identidade. A expressão "identidade múltipla" (KAHN, 1983) mostra que os diferentes componentes da identidade étnica 
se alteram no tempo histórico e nas mudanças de situação social, em contexto de escolhas obrigatórias (SEYFERTH, 2005, p. 22).

Apesar de tantas categorizações, é preciso apontar que os Estados Nacionais têm tratado, invariavelmente, as migrações internacionais de forma generalista, sem considerar os elementos específicos e individuais que as motivaram, fazendo com que muitos solicitantes de refúgio - que utilizam os mesmos mecanismos e rotas dos migrantes voluntários, econômicos, entre outras categorias - sejam prejudicados no acesso ao reconhecimento de seus direitos. Esta realidade, aponta Silva et al. (2017), tem influenciado os debates sobre os fluxos migratórios tanto na academia como nos órgãos protetivos e de promoção de ações para os refugiados. Os autores alegam que desde a segunda metade do século XX, os estudos sobre as migrações alertam para a complexidade da questão social que envolve o tema e para o fato de que sua análise e compreensão não poderiam partir apenas de um viés cognitivo.

Vale aqui ressaltar que, independente da categoria migratória, todos aqueles inseridos em um fluxo misto estão sob risco de sofrerem os mesmos perigos e violações de direitos humanos no curso de suas movimentações. Silva et al. (2017) alertam que isso ocorre, especialmente, em um cenário como o atual, em que as formas de mobilidade passam por um processo de mudança, "no qual se observa, cada vez mais, o aumento dos movimentos frequentes e de curta duração, em substituição aos tradicionais movimentos de longa duração e episódicos” (p. 20). Vivencia-se o período da hipermobilidade (IORIO, PEIXOTO, 2011) e do aumento de fluxos mistos, e a intensa mobilidade do capital e da força de trabalho, favorece a dispersão espacial da produção e "gerando espaços de desemprego, pobreza e emigração (SASSEN, 1988), aos quais também se somam os que fogem de conflitos e perseguições" (SILVA et al. 2017, p. 21).

Migrações contemporâneas são, em grande parte, produzidas e formatadas pelas demandas de um capitalismo globalizado que é ambíguo e contraditório em sua natureza. Esta complexidade tem revelado que as análises e descrições sobre a mobilidade humana têm sido insuficientes. Diferentes eventos migratórios mundiais já apontam que as categorias migratórias propostas têm se revelado insuficientes. Diversos autores - Köhn, 2016; Jameson, 1992, entre outros - têm apontado que já não podemos mais pautar o debate partindo de categorias que explicam a mobilidade de indivíduos a partir de orientações individuais. "Como os mecanismos e dinâmicas do capitalismo global não são visíveis, eles se apresentam como um problema de representação fundamental" (JAMESON, 1992, p.2). Compartilho da perspectiva de Jameson (1992) sobre o 
problema da representação, e vamos além: é preciso descolonizarmos o debate e também o olhar, entendendo que as grandes narrativas ocidentais migratórias precisam ser repensadas diante de um mundo com realidades cada vez mais complexas.

Há uma abordagem crítica emergente nos estudos migratórios que evita a todo custo a produção de teorias econômicas e funcionalistas da mobilidade humana - e que historicamente foram amplamente utilizadas como elemento regulador e de controle. Advoga-se hoje por um entendimento desses grupos enquanto força criativa, um movimento social produtivo dentro das estruturas. Busca-se no debate atual um entendimento dos processos migratórios que priorize as práticas subjetivas, os desejos, as expectativas e os comportamentos dos próprios migrantes" (MEZZADRA, 2011, p. 121).

\section{Perspectivas teóricas}

Em um contexto social tão conturbado, a imagem se mostra como instrumento/recurso analítico para o entendimento do fenômeno proposto. Como entender a relação entre visibilidade e o político no discurso público sobre migração? Como podemos representar visualmente pessoas que são barradas dos seus direitos de representação (política, religiosa, identitária) e como essas representações visuais podem ganhar destaque político? Atualmente o conceito de migração é iminentemente icônico, e isto se aplica não somente aos que se encaixam na categoria de "ilegal". Esta percepção pública sobre o tema é profundamente formatada pelas representações da mídia (KÖHN, 2016, p. 4). Neste sentido, as imagens têm se tornado uma parte integral e relevante no processo de regulação de políticas migratórias: as imagens ajudam a produzir as categorias de "legalidade" e "ilegalidade", elas reforçam estereótipos e mobilizam convicções políticas.

A imagem, no contex to deste artigo, não é pensada como um "veículo" que dá publicidade e faz referência ao imigrante e sua experiência, dando destaque ou revelando o fenômeno. A proposta aqui é pensar o fenômeno migratório com a ajuda das imagens, à luz delas. A proposta é unir a prática visual à reflexão teórica; unir os discursos contidos nas ciências sociais aos conceitos

estéticos. À medida que experimentamos o mundo através de representações e retóricas visuais, o ato de ver e tornar visível assume uma tremenda relevância teórica e política. (KÖHN, 2016, p. 4).

A retórica visual, neste contexto, está focada no entendimento do modo como as imagens comunicam, como elas funcionam em um ambiente social e cultural, e como elas incorporam 
significados. No contexto da mídia, imagens são vistas primeiramente como veículos de informação sobre eventos mundiais importantes, mas muitas vezes a estrutura dos meios de comunicação e as expectativas do leitor tornam a questão mais complexa. É preciso considerar as imagens veiculadas em meios de comunicação como parte de uma intrincada rede pertencente a um fenômeno cultural. A retórica é usualmente considerada como uma chave de persuasão, classicamente utilizada para nos convencer sobre um ponto de vista (na era moderna, muito utilizada para o convencimento de compra). No entanto, podemos considerar que a retórica também tem um papel na formação da identidade e na capacidade de reforçar crenças (WRIGHT, 2011, p. 318).

A imagem aqui se apresenta como objeto de reflexão sobre a responsabilidade de desconstruir estereótipos, buscando novas e transformadoras formas de visibilidade que não reproduzam meramente o discurso visual do governo ou dos meios de comunicação de massa, mas "desafiar a ordem política estabelecida revelando o que propositadamente e deliberadamente escondido, articulando o que ainda não foi dito e sugerindo alternativas viáveis ao status quo" (KÖHN 2016, p. 4).

As representações dos pesquisadores sobre migração ainda esbarram no discurso distorcido produzido pela mídia. As grandes corporações midiáticas frequentemente produzem uma imagem ideológica e distorcida da migração que acabam influenciando inclusive o debate político. $\mathrm{O}$ desafio dos pesquisadores é não somente implementar um modo de produção de conhecimento não hierarquizado que se aproxime das experiências subjetivas destes migrantes, mas também "é preciso produzir um discurso deliberado que atenda a realidade vivida pelos migrantes" (KÖHN, 2016, p. 8).

É importante destacar que somente recentemente cientistas sociais têm começado a participar da expansão de circulação de representações midiáticas da migração. Alan Grosmann e Àine O’Brien (2007, p. 6) foram um dos autores que primeiro forneceram uma visão mais geral deste campo, exaltando a prática da mídia como facilitadora de um entendimento mais profundo das condições vividas, contraditórias e muitas efêmeras que formam a vida e a experiência dos sujeitos migrantes. Neste sentido, a proposta desta discussão é problematizar a fotografia como um (entre outros) recursos de entendimento para nos trazer mais próximos da experiência migrante e como estas imagens podem comunicar este emaranhado de percepções nos processos de escala global. O argumento aqui visa não somente pensar uma nova representação estética de globalização, mas 
também propor uma reavaliação mais ampla do potencial das mídias para o campo das ciências sociais e dos estudos migratórios.

\section{Perspectivas políticas}

Nas últimas duas décadas, assistimos a uma aceleração crescente tanto da migração de pessoas como da circulação de imagens. O poder e o significado das imagens e representações visuais se tornaram uma questão urgente de preocupação acadêmica. Essas abordagens ofereceram uma iconologia crítica dos estereótipos visuais e clichês nos quais a migração é frequentemente retratada. Eles revelam os pressupostos que essas representações implicam e exploram as práticas de exclusão social nelas inscritas.

A maioria dos estudos que se envolvem analiticamente com a representação visual de migrantes no discurso da mídia de massa criticam o uso pesado de distorções e clichês. Terence Wright (2002), por exemplo, analisa quantas fotos de imprensa retratando migrantes referem-se à iconografia cristã para construir imagem do refugiado indefeso e vitimado. Francesca Falk (2010) explora o tema do barco (superlotado) como uma metáfora visual e verbal no discurso sobre refugiados e asilo. Ela mostra como é frequentemente associada à invasão em campanhas políticas anti-migração. Estes e outros trabalhos (KAFEHSY, 2010) revelam como os migrantes são criminalizados ou descritos como vítimas passivas e sem agência. Assim, eles visam descobrir os preconceitos, o "inconsciente" ideológico das representações dos meios de comunicação de massa.

Teun van Djik (1999) tem explorado o campo de estudos sobre racismo e meios de comunicação, enfatizando as representações das minorias étnicas constituídas de imigrantes na mídia impressa em diversos países. O autor tem destacado o silêncio sistemático ou a subvaloração de experiências da vida cotidiana, dos papéis não estereotipados e dos êxitos e contribuições dessas minorias no campo das artes, da política e da economia em favor de imagens negativas e de uma perspectiva de criminalização das experiências migratórias como especificidades do agendamento midiático no contexto das sociedades estudadas. "Nomeados como ilegais, clandestinos, irregulares, refugiados, deportados, os imigrantes são alvos de uma semantização negativa e 'policialesca' que inclui intolerância, violência, desemprego, isolamento, preconceito, pobreza, condenação, fiscalização, deportação, expulsão, tráfico ou detenção” (COGO, 2001, p. 17). Os 
títulos de algumas das matérias mapeadas sugerem a ênfase em uma "criminalização" em que os imigrantes, embora cheguem a ocupar a posição de sujeito, aparecem, na maioria das vezes, como "pacientes" ou "experimentadores" das ações de "outros", geralmente as autoridades ou os aparatos policiais.

O entendimento sobre a construção de uma agenda midiática sobre a experiência migratória começa a ser construído a partir de uma aproximação empírica inicial com aquilo que Cogo (2001, p.15) vai chamar de "ofertas de sentido". A mídia impressa se constitui, segundo ela, em esfera privilegiada de oferta de "sentidos" a autoridades, especialistas e demais atores sociais incumbidos da formulação de políticas e da tomada de decisões em diferentes campos sociais. No entanto, para Van Dijk (1999), o poder dos meios de comunicação não deve ser compreendido em termos de "efeitos" simplistas. Embora não faça uma reflexão sobre recepção, o autor argumenta que as diferenças socioeconômicas e socioculturais interferem na forma como as pessoas interpretam, representam e avaliam as matérias jornalísticas e os eventos noticiosos e, consequentemente, em como formam opiniões, atitudes e ideologias diferentes. Nesse sentido, é importante ressaltar que os meios de comunicação são extensões das lutas e das partilhas simbólicas da sociedade, como lembra Maigret (2010, p. 309): “Os meios de comunicação são espaços onde atuam a formação, a reprodução e a contestação de conjunto de práticas e de crenças, misturando indissociavelmente poder e cultura, e cada um desses elementos se lê no outro."

Torna-se cada vez mais importante analisar não somente a capacidade de imagens de criarem novos discursos, mas também a necessidade de examinar o contexto social e institucional restritos à sua função. É fato que o poder da mídia tem recebido pouca atenção nas pesquisas sobre a representação da migração (WRIGHT, 2002). Tomo como exemplo a reflexão proposta por Malkki (1995, p. 9), que apontou que "retratos fotográficos de refugiados são, em nossos dias, extremamente abundantes. A maioria dos leitores provavelmente já viu essas fotos, e a maioria de nós tem um forte sentido visual de como é 'um refugiado". A representação visual de migrantes desempenha um papel essencial, mas negligenciado, na formação do estereótipo destes grupos.

Nas ciências sociais e humanidades, de um modo geral, há uma tendência a desconsiderar o impacto político que nossas representações possam gerar. Arjuan Appadurai (1988) reivindicou que não deveríamos reduzir nossos trabalhos a meras descrições do presente, e sim que imaginemos possibilidades e futuros possíveis mais do que nos submetermos às imposições de mudanças 
externas. A experiência dos conflitos de nosso tempo, seja em torno de questões de autonomia, soberania ou nacionalidade, é moldada principalmente por representações visuais e grande parte da política contemporânea é, portanto, conduzida por meio da cultura visual. Reconhecendo o quanto as imagens se tornam participantes autônomas na construção do significado social, lanço mão da discussão proposta por Roland Bleiker (2012), que defende uma forma mais estética do pensamento político. $\mathrm{O}$ autor propõe um engajamento estético com o mundo político com base na compreensão de que fontes estéticas oferecem insights valiosos que outros métodos científicos de investigação são incapazes de explicar.

Compartilho da perspectiva de Ariella Azoulay (2008), que propõe uma ontologia política da representação visual que promove a compreensão das imagens como agentes ativos nas relações sociais. Ao nortear seu trabalho a partir de fotografias de palestinos nos territórios ocupados por Israel, Azoulay (2008) descreve como as imagens podem oferecer um espaço de cidadania para aqueles que não pertencem ou não recebem proteção do poder soberano de um estado-nação. A autora vê um "contrato civil" inscrito na fotografia, onde o fotógrafo, o fotografado e o observador da fotografia participam. Como nenhum fotógrafo pode reivindicar a propriedade do que aparece na fotografia nem determinar seu único significado, as pessoas fotografadas podem usar sua imagem para reivindicar os direitos que lhes são negados pelo Estado. Os espectadores são tratados pela fotografia como "espectadores universais" que estão ligados em uma forma de dever cívico com o fotografado e, portanto, são convidados a assumir a responsabilidade por testemunhar o insuportável” (p. 18). A representação visual pode, portanto, oferecer àqueles que são excluídos da representação política uma primeira chance de articular as maneiras pelas quais foram dominados. Para a autora, o indivíduo se torna um cidadão por meio da fotografia - não apenas por ser fotografado, mas em virtude de ser visível em um mundo em que a mídia visual dá reconhecimento público a potencialmente todos, em que (dada a onipresença das câmeras como ferramentas para as massas) a fotografia é sempre um "evento potencial" (p. 22). A fotografia permite, assim, que os seus cidadãos se façam aparecer em público, se apresentem perante ele e dialoguem com o público através das imagens.

Para Azoulay (2008), no entanto, as imagens documentais nunca podem ser "muito estéticas", porque sempre documentam as relações e negociações entre o fotógrafo e os sujeitos, sempre retratam o contexto político em que foram criadas. A fotografia na percepção da autora é 
sempre o produto de um encontro entre cidadãos: suas análises de imagens da história da fotografia exploram em detalhes como os fotografados têm usado continuamente o "evento da fotografia" para contestar as injustiças feitas a eles em público. Azoulay (2008) desmonta assim o binário entre o espaço do político (que, para ela, é inerente a todo encontro entre os seres humanos) e o espaço da estética, tornando esses dois espaços um só.

\section{Considerações finais}

Cabe aqui a utilização do conceito de "cidadania visual", proposto por Azoulay (2012). A autora aponta que este conceito foi adotado por outros estudiosos que começaram a analisar como "as práticas audiovisuais condicionam, exacerbam, impedem ou tornam (in) consequentes os direitos, privilégios, deveres e direitos entre as pessoas que estão incluídas e excluídos, vistos e invisíveis, ouvidos e silenciados nas práticas jornalísticas, nas campanhas de ação direta, nas propagandas comerciais, no ambiente construído e assim por diante” (TELESCA, 2013, p. 339). Neste sentido, aponto para a necessidade de repensar as maneiras pelas quais as práticas audiovisuais medeiam a ação política (e vice-versa) e para a importância de examinar os processos complexos pelos quais os migrantes "ilegais" são tornados anônimos na esfera pública e invisíveis aos olhos da lei em vigor.

Para compreender este emaranhado de representações visuais como processos políticos, no entanto, aponto para a necessidade não apenas de analisar o conteúdo discursivo dessas representações, mas também os próprios atos de visualização. Visibilidade e invisibilidade devem ser entendidas antes de tudo como modos políticos de existência, e a representação deve ser entendida também em termos visuais e políticos, lembrando sempre da relação entre visibilidade e poder. Compartilho da percepção de Köhn (2016) de que a existência de migrantes na esfera pública é constituída por uma dialética da in/visibilidade, do encobrimento e da exposição. A visibilidade proeminente que os migrantes recebem na mídia como estereótipos os torna efetivamente invisíveis como indivíduos. "Além disso, existe uma ligação perturbadora entre as representações da mídia e a política do estado de vigilância e controle de migrantes. Sua visualização é, portanto, potencialmente perigosa para muitos migrantes, pois entra em conflito com sua necessidade de permanecer invisíveis” (KÖHN, 2016, p. 31). 
No contexto de uma retórica desumanizante em torno da imigração e do crescente cansaço da compaixão, o sucesso das imagens em sua capacidade de estimular a empatia por meio da narração de histórias é inegável. Em vez de solidificar as fronteiras políticas divididas entre "nós" e "eles", a fotografia aproxima os dois, atuando como um espelho para universalizar a experiência do migrante. O potencial da fotografia na crise migratória é, no entanto, frequentemente limitado aos seus benefícios terapêuticos ou culturais e sua capacidade de apresentar refugiados e migrantes como mais do que a soma de seus estereótipos. Embora eu acredite que esse é um caminho viável, a fotografia também pode ajudar a imaginar possibilidades impossíveis de outra forma abandonadas na política e no direito, que ainda poderiam se firmar e produzir soluções concretas, ou seja, novos modelos de cidadania ou a completa dissolução das fronteiras globais concebidas. Com poucos avanços em direção a uma resposta verdadeiramente humanitária à crise migratória, é esse potencial novo e radical que não deve mais permanecer subestimado.

Encerro este ensaio compartilhando da perspectiva de Grau e Hinterwaldner (2021, p. 10) a ideia contemporânea de uma iconografia política, especialmente quando chamam a atenção do leitor para o papel que a fotografia passa a desempenhar cada vez mais na atualidade a respeito das questões sociopolíticas de hoje, "como as mudanças climáticas, finanças, migração humana e sociedade de vigilância" (p. 10).

\section{Referências bibliográficas}

APPADURAI, A. Putting hierarchy in its place. Cultural anthropology, v. 3, n. 1, p. 36-49, 1988. AZOUlAY, A. The Civil Contract of Photography. Cambridge: MIT Press, 2008. . Civil Imagination: A Political Ontology of Photography. London: Verso, 2012.

BAENINGER, R. (Org.). Imigração Boliviana no Brasil. Núcleo de Estudos de PopulaçãoNepo/Unicamp; Fapesp; CNPq; Unfpa, 2012.

BLEIKER, R. Aesthetics and World Politics. New York: Palgrave Macmillan, 2012.

CASTLES, S.; HAAS, H.; MILLER, M. The Age of Migration: International Population Movements in the Modern World. New York: Guilford Press, 2014. 
COGO, D. Mídia, imigração e interculturalidade: mapeando as estratégias de midiatização dos processos migratórios e das falas imigrantes no contexto brasileiro. Comun. Inf., v. 4, n.

1/2, p.11-32, jan. dez. 2001.

DURAND, J.; LUSSI, C. Metodologia e teorias no estudo das migrações. Jundiaí: Paco Editorial, 2015.

FALK, F. Invasion, Infection, Invisibility: An Iconology of Illegalized Immigration. In: BISCHOFF, C.; FALK, F.; KAFEHSY, S. (eds.). Images of Illegalized Immigration: Towards a Critical Iconology of Politics. Bielefeld: Transcript, 2010.

GLICK-SCHILLER, N. et al. Transmigrants and nation-state; something old and something new in the U.S. immigrant experience. Texto apresentado no CEMI/UNICAMP, 1997.

GRAU, O.; HINTERWALDNER, I. (eds.). Retracing Political Dimensions: Strategies in Contemporary New Media Art. Berlin/Boston: Walter De Gruyter GmbH, 2021.

GROSSMAN, A.; O'BRIEN (eds.). Projecting migration: transcultural documentary practice. London and New York: Wallflower Press, 2007.

IORIO, J.; PEIXOTO, J. Crise, imigração e mercado de trabalho em Portugal: retorno, regulação ou resistência. Lisboa: Princípia, 2011.

JAMESON, F. The Geopolitical aesthetic: cinema and Space ain the World System. Bloomington: Indiana University Press, 1992.

KAHN, V. S. et al. Formation of consciousness. In: FRIED, C. (org.). Minorities: community and identity. Berlin: Springer, 1983.

KAFEHSY, S. Images of Victims in Trafficking in Women: The Euro Campaign Against Trafficking in Women in Switzerland. In: BISCHOFF, C.; FALK, F.; KAFEHSY, S. (eds.) Images of Illegalized Immigration. Towards a Critical Iconology of Politics. Bielefeld: Transcript, 2010.

KÖHN, Steffen. Mediating mobility: visual anthropology in the age of migration. New York: Wallflower Press: 2016.

MAIGRET, E. Sociologia da comunicação e das mídias. São Paulo: Senac, 2010.

MALKKI, L. Purity and Exile: Violence, memory and national cosmology among Hutu refugees in Tanzania. Chicago: Chicago University Press, 1995.

MEZZADRA, S. The gaze of autonomy: capitalism, migration and social struggles. In: SQUIRE, V. (ed.). The Contested Politics of mobility: borderzone and irregularity. London: Routledge, 2011.

NETO, H. P.; FERREIRA, A. Cruzando fronteiras disciplinares: um panorama dos estudos migratórios. Rio de Janeiro: Revan, 2005. 
SANTOS, M.; PETRUS, R.; LOUREIRO, A. (orgs.). Recortes interdisciplinares sobre migrações e deslocamentos. Rio de Janeiro: Léo Christiano Editorial, 2014.

SASSEN, S. The mobility of labor and capital. Cambridge: University Press, 1988.

SILVA, J.C.J. et al. Os fluxos migratórios mistos e os entraves à proteção aos refugiados. Rev. Bras. Est. Pop., Belo Horizonte, v. 34, n. 1, p. 15-30, jan. abr. 2017.

SEYFERTH, G. Imigração e (re)construção de identidades étnicas. In: NETO, H.; FERREIRA, P. (orgs.). Cruzando fronteiras disciplinares: um panorama dos estudos migratórios. Rio de Janeiro: Revan, 2005.

TELESCA, J. E. Preface: What Is Visual Citizenship? Humanity: An International Journal of Human Rights, Humanitarianism, and Development. v. 4, n. 3, p. 339-43, 2013.

VAN DIJK, T. Editorial - Discourse and racism. Discourse and Society, p. 147. 1999.

WRIGHT, T. Moving Images: The Media Representation of Refugees. Visual Studies, v. 17, n. 1, p. 53-66, 2002.

. Press photography and visual rhetoric. In: MARGOLIS, E.; PAUWELS, L. (eds.). The Sage handbook of visual research methods. London: Sage, 2011. 